\title{
Earthquake in Colombia: the tragedy of the coffee growing region. Health impact and lessons for the health sector
}

\author{
Helena E Restrepo
}

Carrera 2 Oeste, 11-05

Apt, 302 Cali,

Colombia SA

This paper was written by Helena E Restrepo, based on interviews with the Health Directors of Quindío and Armenia, Jaime Gallego (Chief of Quindío Health Institute) (Secretary of Health of Armenia City), and on the review of reports and documents produced by their collaborators, advisors and professionals from different organisations and institutions working in the area affected by the earthquake.

Correspondence to:

Dr Restrepo

(restrhel@andinet.com)

Accepted for publication 20 September 1999 and Olga A Nieto

The paper describes three stages of the earthquake and its consequences to health, with emphasis on the public health implications:

1 The first impact.

2 The process of the subsequent two month period (25 January-25 March).

3 The current situation (at April 1999) and future perspectives.

To understand the size of the devastated area, it is important to clarify that the region known as "Departmento del Quindío" corresponds, according to the political and administrative division of Colombian territory, to several small towns and its capital city, Armenia. The neighbouring city of Pereira, capital of the Departmento of Risaralda, and several towns of that and other nearby Departmentos (Valle, Tolima), were also affected, but to a lesser extent. The whole area of influence of the telluric movement is know as "Eje Cafetero" (Coffee Axes), because it is here that most Colombian Coffee, some of the best quality in the world, is produced. This area is located within the country's central chain of mountains (fig 1).

Before the tragedy, Armenia had a population of 296330 inhabitants, with the whole

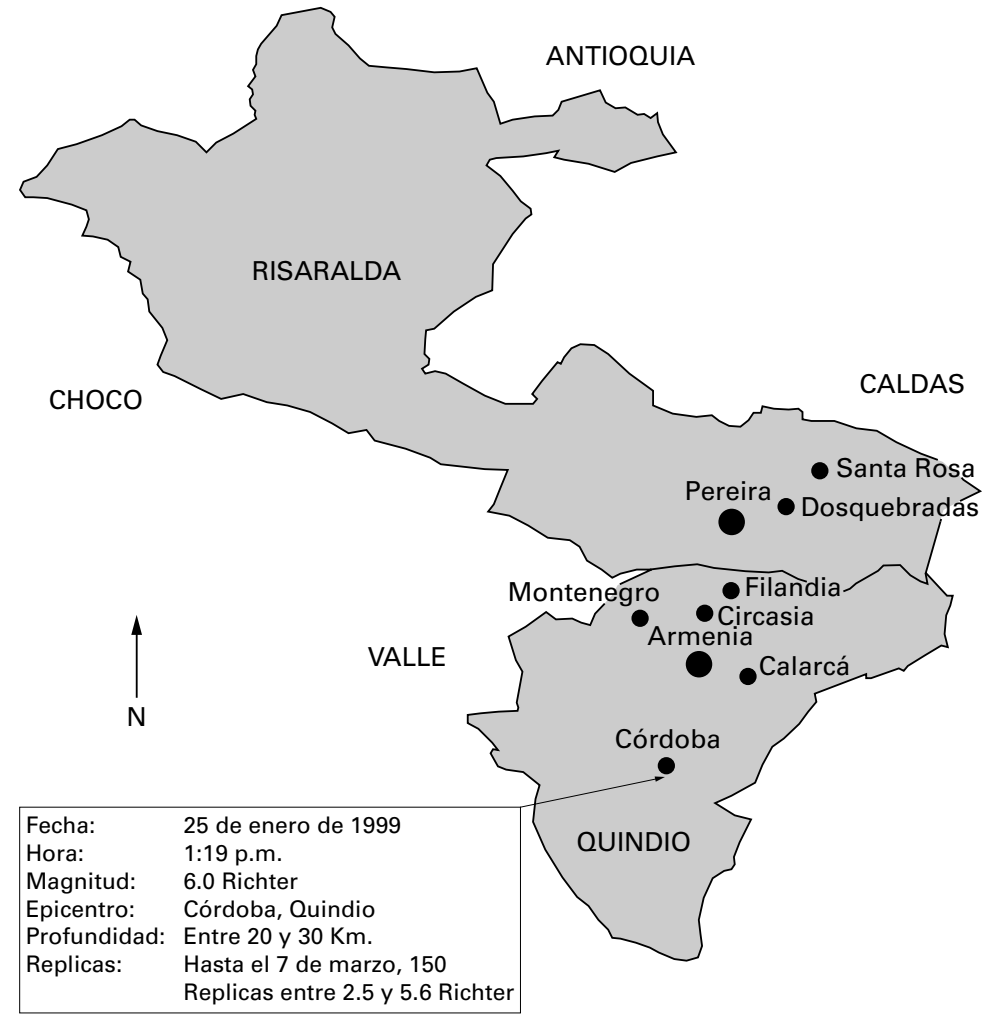

Figure 1 Map of area affected by the earthquake.
Departmento of Quindío having a population of approximately 500000 .

\section{First impact}

The earthquake occurred at $119 \mathrm{pm}$ on Monday, 25 January 1999, and had an intensity of 6.2 points on the Richter scale. The focus was located in the municipality of Cordoba, 20 kilometres from Armenia, and had a depth of two to three thousand metres. Experts consider that it was this short distance from the surface that caused the shaking to be so strong. Although 28 towns or municipalities, including Armenia, were severely damaged by the earthquake, the worst effects were in Armenia itself and surrounding towns. The aftershocks that followed the main earthquake, especially one at $540 \mathrm{pm}$ on the same day, brought down numerous houses and buildings that had been partially damaged by the first movement.

The consequences of the catastrophe were devastating, mainly because of the loss of people's property and belongings: around $70 \%$ of Armenian houses vanished, and in some neighbouring towns the percentage was more than $80 \%$. In the rural area, the proportion of lost houses was also $80 \%$. The total number of deaths was estimated at 1184, and the total injured at more than 5000 (see figs 2-6).

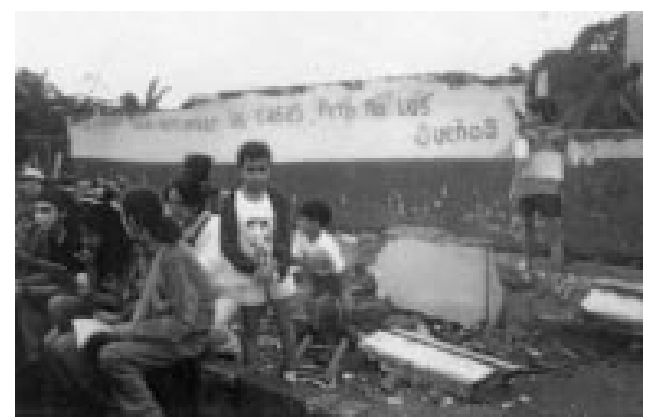

Figure 2 Children in camps.

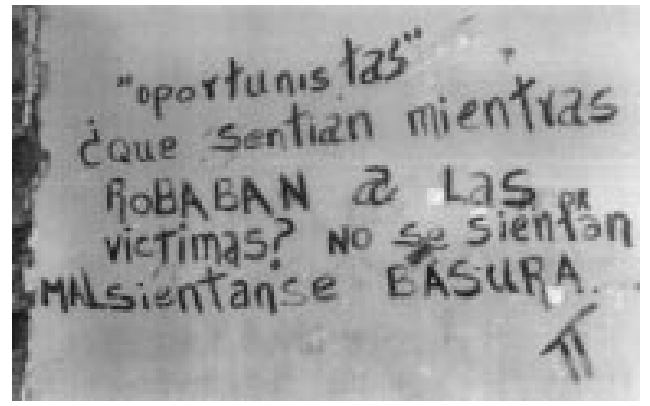

Figure 3 The bandits that stole from the victims should feel like the worst. 


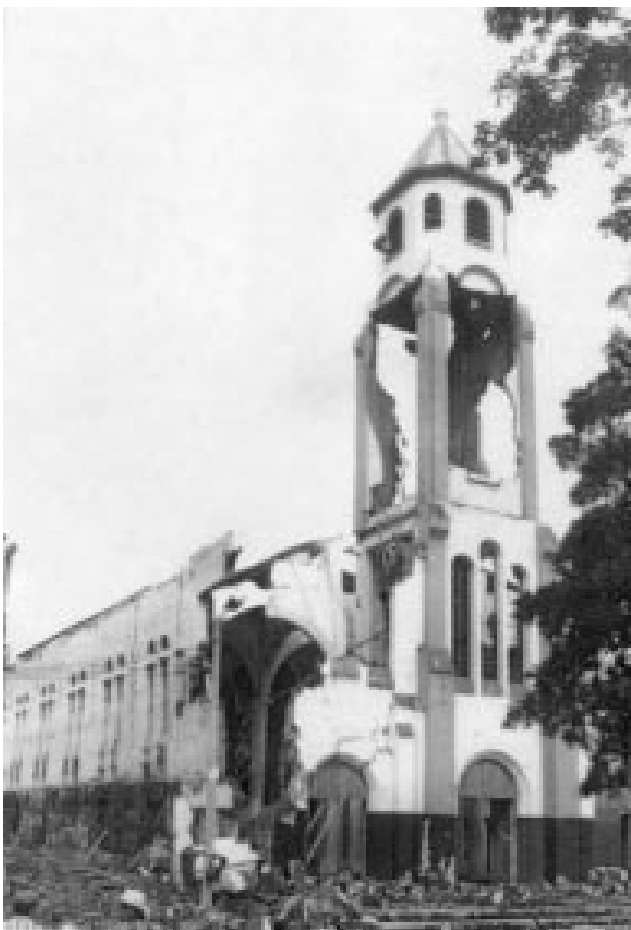

Figure 4 Church of one of the affected towns.

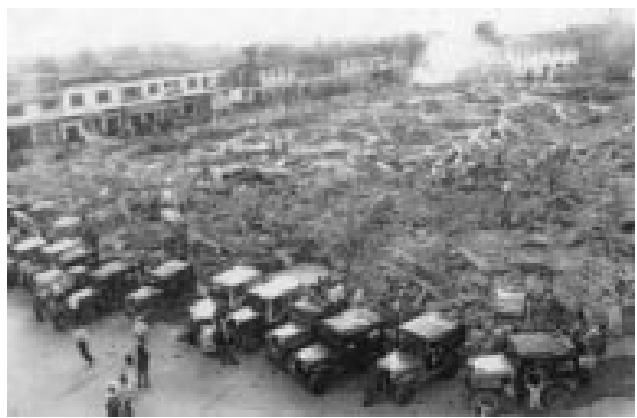

Figure 5 Destruction of the central park of Calarcá.

Those responsible for public health describe the immediate impact of the event on the health care sector as of great chaos and confusion. Emergency care was disorganised and health personnel were shocked, not knowing how to respond to the needs of so many injured persons. However, despite the magnitude and severity of the tragedy and the huge impact on the health care sector (destruction of facilities, exaggerated demand for medical care and affliction of health workers and their families) the health authorities organised strategic places for injured people to be received and given treatments in Armenia and in every affected town.

In the opinion of several health care professionals, the greatest problem for health care institutions was the absence of an immediate alternative communication network - to know what was going on in the different towns-however the Regional Hospital and the Red Cross tried to solve the problem, and the Ministry of Health's alternative radio system reinforced the network. The Ministry of Health also organised continuous aeroplane transportation between Armenia and Bogotá (Colombia's capital city), and this

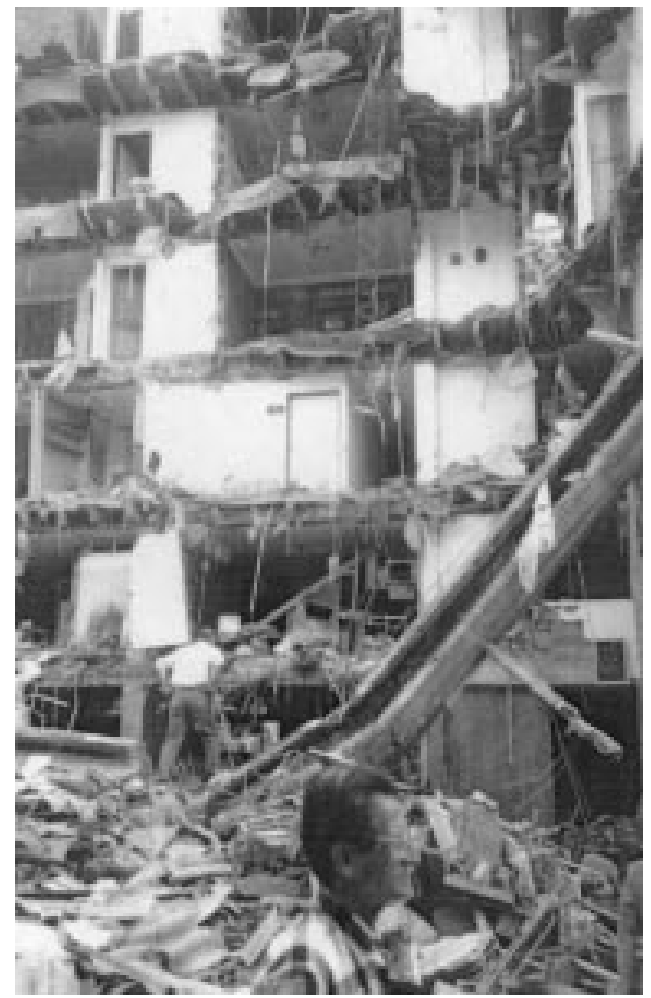

Figure 6 Neighbourhood of Armenia.

was crucial to the needs of high risk patients during the first 72 hours after the earthquake.

Although lacking in both personnel trained in disaster emergency care (nurses, general practitioners did not know how to classify patients in catastrophic events) and materials and supplies (oxygen, orthopaedic equipment, etc), adequate medical care seems to have been given to all injuries and trauma through the hospitals in the Quindío area and other centres in the principal cities of Colombia. In addition, the assistance of the professors and medical students of the University of Quindío during the first hours was very useful, and so too was the collaboration of physicians and ambulances from Cali, Bogotá and Medellin.

The buildings and infrastructure of the health care system were severely affected, but the main hospitals in Armenia and Pereira had little damage and could continue functioning. International aid was mobilised quickly, and some transitory hospitals were installed.

A violent outburst of social unrest occurred on the night of the second day, caused by the anger and despair of the people, and also by delinquents trying to take advantage of the dreadful situation. This event had an additional impact on health services.

In summary, during the first 72 hours the impact of the earthquake was mainly on the emergency health services, but national and international mobilisation was very effective and successful. The lessons learned from this phase were related to the need for better training of health personnel in what to do in the immediate moment of a disaster, especially the need to organise emergency care and also to solve communication problems. The contingency plans and protocols that were quickly 
developed, with guidelines for attending injured patients and for solving communication problems, were crucial during this period.

From the Armenian experience, we can conclude that the existence of a Disaster Committee with little experience of this type of catastrophe is not enough; there should be well trained personnel in different sectors and institutions. An ironic fact was that the Disaster Committee of Armenia used to hold their meetings in the fire station building, which was destroyed killing 11 firemen.

\section{The process of facing the catastrophe-the first two months}

There is consensus in the public health sector that this was the hardest period, and when support was most needed-not only in terms of equipment and other materials, but very importantly in psychological and moral support. After several days without rest, and without having time to attend to the loss of their own homes and sometimes family losses and injuries, health workers suffered a great deal of stress. In addition, they were dealing with the indescribable despair and suffering of people who had lost everything. Psychiatric and psychological resources were completely insufficient. Fortunately, public health leaders were aware of the importance of mental health programmes and resources for facing this kind of disaster, and a Technical Committee of Mental Health was organised by the Quindio health authorities during the first week. The committee gave priority to the communities of the most damaged towns, and then secondly to health workers, through short intervention approaches; valuable resources in psychology and psychiatry were mobilised from universities and services throughout the country.

Another burden was the organisation of "transitory living" in tents and "alojamientos" (multi-family spaces), with difficulty in the provision of sanitary services, water and food. Fears about epidemics were high, but no epidemic of any infectious disease materialised, including diarrhoeal disease, dengue and malaria as was feared. However, situations of conflict occurred among people, and violent incidents were frequent. Patients with chronic disease such as hypertension, diabetes and epilepsy suffered from a lack of medication.

It is calculated that more than 700000 people in the devastated area were in a serious condition for one reason or another, and that around 30000 people left the area for neighbouring cities; however most of these returned to seek government monetary aid. The displaced population increased Colombia's existing problem of displacement from rural areas to the cities caused by violence.

Those responsible for public health undertook a number of steps to deal with the health problems:

- The coordination of integrated work of health institutions under the direction of the Quindio Health Institute and the Secretary of Health of Armenia.

- The organisation of multidisciplinary teams to provide services within primary care in each municipality; each team had an acting coordinator for each 24 hours. One of the favourable conditions was the previous existence of a very solid primary health care approach in Quindío.

- The organisation of epidemiological surveillance and campaigns to prevent epidemic outbreaks of infectious diseases; this was supported with the advice of the Ministry of Health and National Institute of Health, the Pan American Health Organisation (PAHO), the World Health Organisation (WHO) and other international experts.

- The design of a Sentinel Community Surveillance System using unified forms of data collection.

- The design of a Contingency Plan for the first month after the disaster, and daily evaluation of its accomplishments.

- The search for psychological and psychiatric resources in order to meet the great demand for mental health support for families, especially children.

- Attention to the equitable provision of services, according to the principles of the new National Social Security System for Health.

- Strengthening health promotion and disease prevention and interdisciplinary work with sociologists ${ }^{\star}$, social workers, psychologists, communications experts, nurses and physicians. Alternative methods of social communication were used to give preventive messages to communities in every municipality. Resources provided by PAHO and the National Public Health School of Medellin were very supportive in these activities. A very interesting feature was the contribution of a young community activist who was a student of educational technology.

The agreement of the whole health sector to accept only one direction and unique plan of action was considered to be an asset. The same applied to the organisation of primary health care teams for each town and neighbourhood. The quick mobilisation of valuable national and international resources with expertise in disaster and sanitary management and epidemiological surveillance was a key factor in the control of epidemics and for decision taking; the Ministry of Health and National Institute of Health of Colombia and PAHO/WHO played a very important part, and the Cuban experts that had been supporting local personnel were considered very helpful. One of the positive results was that the dengue epidemic that had already been present in the region before the earthquake was controlled.

On the other hand, several problems were detected in this period, such as the following:

- The presence of so many advisors and voluntary helpers, who had different approaches and who were from different cultural backgrounds, sometimes created confusion. In addition, the provision of

\footnotetext{
$\star$ The advice and collaboration of sociologists from the Universidad Tecnológica of Pereira has been excellent for identifying community needs and values and for reinforcing social participation.
} 


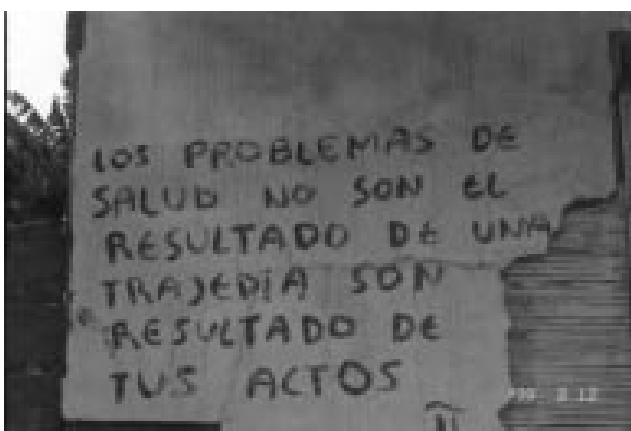

Figure 7 Health problems are not caused by the tragedy, they are caused by your behaviour.

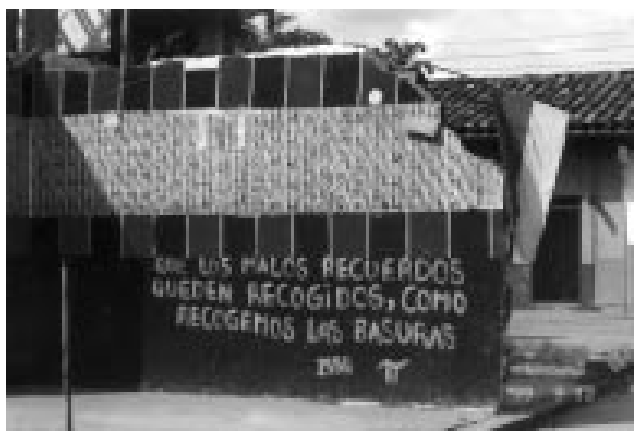

Figure 8 The bad memories should be hidden like waste.

lodging, transportation and food was sometimes a burden for local people. The recommendation concerning groups of helpers is that they should be self sufficient in regard to all their needs. The coordination of all voluntary and external advisors should be the responsibility of local health authorities.

- Donations of drugs and materials that were not useful, or in bad condition, became more of a problem than an aid. The correct classification of utilities and drugs before they are sent would be desirable, and should be managed by local health authorities.

- The weakness of programmes for physical rehabilitation.

- Increasing diarrhoeal events were attributable mostly to alimentary problems, rather than to infectious agents; the kind of food donated and provided by the government was very different to the usual type consumed by this particular cultural group, whose diet is based on corn, beans, plantains and rice. However, a real epidemic of diarrhoea was not present at any time.

- The high frequency of dermatitis and mild skin infections, resulting from low levels of water provision for hygienic measures and inadequate conditions for taking showers. However, this never became an epidemic and was easily controlled.

- The difficulty in obtaining the understanding and commitment of other government departments outside the health department for sharing responsibilities and for organising multisectoral actions to improve health conditions. This underlines the importance of distinguishing between health and disease in public health emergencies.

- One of the more evident needs is to develop well organised and effective health commu-

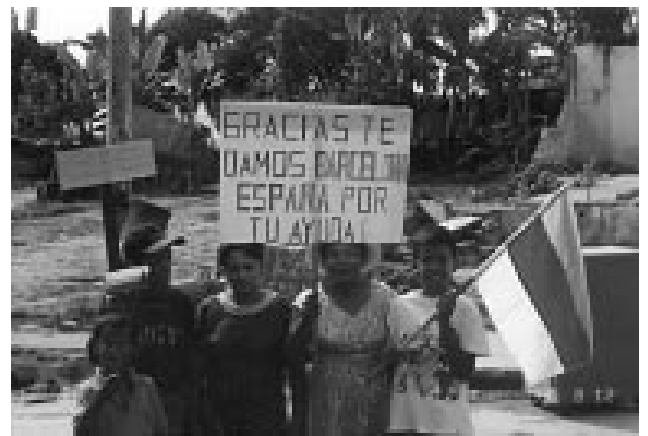

Figure 9 Thank you Barcelona, Spain for your help.

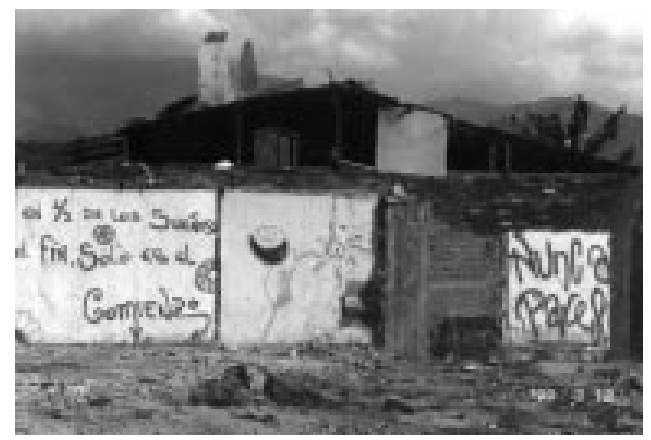

Figure 10 In the meaning of dreams, the end is only the beginning. Never stop.

nication and health education programmes; expertise in these areas is very poor in the Colombian public health system.

- The most critical problem was the absence of mental health programmes distinct from psychiatric care-that is, mental health promotion based on social support, social participation and family counselling. The lack of trained personnel for these kinds of programmes was most evident.

According to the opinion of the main leaders of the health care sector, many positive lessons can be identified from this whole experience, and their recommendations are very thoughtful; one example is the recommendation for implementing intersectoral strategies very soon after the disaster to deal with social, economic and health problems.

Other lessons from this period are related mainly to the need for good, solid programmes of health promotion and disease prevention, with emphasis on mental health, social participation and solidarity. The efforts of health professionals are insufficient to deal with community needs in such extreme socioeconomic crises; latent poverty and structural problems were aroused, and the health care sector suffered a major impact in consequence.

The other important lesson is the need for quick and effective solutions to basic sanitary conditions. Water provision and garbage management is critical. Fortunately, the Quindío response was very effective in this respect.

Current situation and future perspectives By April, the situation of the health sector could be described as stable; the primary health care network was very active and functioned well in every town and in the Armenia neighbourhoods. The public hospitals 
of Armenia were functioning with some difficulties, but had the capacity to attend the whole population. The institutions of the new National Health System-organised after health reform law in 1993-which are of private, public and mixed origin, were emerging again and organising medical care for their affiliates. In general terms, medical care was in an acceptable condition.

The public health authorities are now working very hard trying to take advantage of the new situation to thoroughly evaluate the whole role of public health leaders and the organisation of the system; they see "an opportunity to rethink the public health structure and its functioning" (Gallego). Health surveillance as an integrated concept is one of their priorities, and the creation of a sound and efficient information system for policy making is seen as a cornerstone for that purpose. Health promotion and disease prevention projects and programmes are seen as essential for future development. The need for better communication, public information and health education programmes is recognised, and there is increasing awareness about their key role in a new public health practice that is orientated to tackle the complexity of modern health problems. By the same token, socioecological models are seen as the future models for public health action.

As a result of these new perspectives, there is a clear awareness about the need for innovative projects and programmes in health promotion. An example of this is the new project that is being developed by the Quindío Health Institute on social communication for health, using the creative capacity of the student of educational technology mentioned earlier, which uses graffiti for increasing solidarity, social and moral support in common "alojamientos" (camps) (see figs 7-10.) The same consideration applies to the emphasis that is being put on intersectoral approaches and multidisciplinary teamwork in devastated localities. So far, based on the experience of the Antioquia group that has adopted the town of La Tebaida, where the destruction was almost total, the results of these approaches are very promisingt.

Every day, public health professionals in Quindío are becoming more concerned about the lack of qualified human resources in health promotion methodologies and strategies, and the need for establishing good training programmes in modern public health.

As final conclusions and lessons for others who might be faced with similar tragic circumstances, the Quindío health authorities have emphasised the importance of developing robust contingency plans that involve all the main agencies, including the health sector. The existence of protocols and procedure manuals, as well as a good programme of exercises for simulating catastrophic events would reduce uncertainty and assure efficient and effective kinds of resources (technical, financial, etc) from diverse governmental, non-governmental and private organisations and institutions. However, the most valuable resources in these situations are well informed communities with solid processes of participation and "the existence of public policies to mitigate social and economic burdens" (Nieto). Public health workers should fight for those kinds of policies, and strengthen social participation and the empowerment of community groups.

The author expresses her gratitude to Cruz H Montoya (Nurse Master in Health Promotion) and Sandra Lopez (Social Communication Student) for their excellent support and dedication to the collection of the documentation for this paper, and also to doctors Jaime Gallego and Olga A Nieto for their time and interest in sharing their suffering and valuable experience with other people. They are the true motivators of the Quindío and Armenia public health recovery process.

tThe State (Departmento) of Antioquia concentrated all its help in one town, mobilising the different kind of resources (technical, financial, etc) from diverse governmental, non-governmental and private organisations and institutions. 